\title{
PELATIHAN TEKNOLOGI KIMIA TERAPAN PEMBUATAN SABUN CAIR CUCI PIRING, SABUN MANDI HERBAL DAN TEPUNG AMPAS KELAPA IBU-IBU 'AISYIYAH RANTING PERUMNAS CONDONG CATUR, DEPOK, SLEMAN
}

\author{
Oleh: \\ Siti Salamah, Endah Sulistiawati, Agus Aktawan \\ Program Studi Teknik Kimia \\ Universitas Ahmad Dahlan \\ E-mail: sitisalamah@che.uad.ac.id
}

\begin{abstract}
Ringasan
Usaha rumah makan skala menengah maupun sederhana berkembang sangat baik di area depok, sleman, yogyakarta dimana yogyakarta merupakan kota pelajar dan kota pariwisata. Banyaknya konsumen yang berasal dari mahasiswa dan wisatawan serta perlu terjaganya kebersihan terutama alat makan sehingga kebutuhan akan sabun cair semakin meningkat. Kebutuhan akan sabun mandi juga mengalami peningkatan terutama dari industri perhotelan dan losmen. Peningkatan kebutuhan akan sabun cair dan sabun mandi ini perlu dipahami oleh warga sekitar khususnya dan mengetahui cara membuatnya, dengan harapan dapat dikembangkan menjadi produksi skala rumah tangga (pemberdayaan ekonomi). Pengabdian masayarakat ini melatih kelompok ibu-ibu 'Aisyiah perumnas condongcatur, depok. Ibu-ibu diberikan pemahaman tentang teknologi kimia terapan tentang pembuatan sabun cair cuci piring, sabun mandi herbal dan tepung ampas kelapa yang berkualitas. Sabun cair terbuat dari texapon, sodium sulfat, comperland, asam sitrat, EDTA, parfum, propilen glikol dan aquades yang dicampur, diaduk secara perlahan dan kontinyu. Sabun cair yang terbentuk dimasukkan dalam botol-botol. Sabun mandi herbal terdiri dari $\mathrm{NaOH}$, aquades, castor oil, minyak kelapa dan minyak zaitun dimana bahan-bahan tersebut dicampur sesuai prosedurnya. Sabun dibentuk dalam cetakan dan ditunggu hingga 7 hari agar saponifikasi terjadi. Tepung ampas kelapa dibuat dari ampas parutan kelapa yang telah diambil santannya, ampas kelapa tersebut disangrai sampai betul-betul kering lalu diblender sampai halus seperti tepung. Ibu-ibu sangat antusias mengikuti pelatihan yang menghasilkan sabun cuci piring 6 botol (volume $150 \mathrm{ml}$ ) dari 1 resep. Sabun mandi herbal, 1 resep bahan menjadi 12 buah sabun dengan ukuran diameter $3 \mathrm{~cm} .1 \mathrm{~kg}$ kelapa parut akan diperoleh 500 gram tepung ampas kelapa berkualitas.
\end{abstract}

Keywords: Sabun Cair, Sabun Mandi Herbal, Tepung Ampas Kelapa.

Abstract

Small and medium-scale restaurant business is growing very well in depok, sleman, yogyakarta where yogyakarta is a student city and a tourism city. The number of consumers who come from students and tourists and need to maintain hygiene, especially eating utensils so the need for liquid soap is increasing. The need for bath soap has also increased especially from the hospitality industry and the inn. Increasing the need for liquid soap and bath soap needs to be understood by the local people in particular and know how to make it, in the hope of being developed into household scale production (economic empowerment). The devotion of this community trains the group of mothers' Aisyiah perumnas condongcatur, depok. Mothers are given an understanding of applied chemical technology on the manufacture of dishwashing liquid soap, herbal bath soap and quality coconut milk dregs. Liquid soap is made of texapon, sodium sulphate, comperland, citric acid, EDTA, perfumes, propylene glycol and aquades are mixed, stirred slowly and continuously. The liquid soap formed is inserted in the bottles. Herbal bath soaps consist of $\mathrm{NaOH}$, aquades, castor oil, coconut oil and olive oil where the ingredients are mixed according to the procedure. The soap is formed in the mold and is waited for up to 7 days for saponification to occur. Coconut 
dregs flour made from coconut shredded pulp that has been taken coconut milk, coconut pulp is roasted until completely dry and blend until smooth as flour. Ladies are very enthusiastic about the training that produces dishwashing soap 6 bottles (volume $150 \mathrm{ml}$ ) from 1 recipe. Herbal bath soap, 1 recipe material to 12 pieces of soap with a diameter of $3 \mathrm{~cm} .1 \mathrm{~kg}$ of grated coconut will get 500 gram of quality coconut dregs flour.

Keywords: Liquid Soap, Herbal Bath Soap, Coconut Flour Flour.

\section{A. PENDAHULUAN}

Pelatihan Teknologi Kimia Terapan merupakan bentuk Pengabdian kepada Masyarakat dan merupakan salah satu dharma dari tridharma perguruan tinggi yang harus dijalankan dengan tujuan ilmu teoritis yang dipelajari di kampus dapat diterapkan di masyarakat dan dapat meningkatkan kesejahteraan masyarakat. Selain itu diharapkan dapat terwujud kerjasama antara Universitas Ahmad Dahlan dengan masyarakat, sehingga kegiatan ini sebagai media sosialisasi kepada masyarakat.

Ibu-ibu 'Aisyiyah Pimpinan Ranting Perumnas Condongcatur Depok Sleman, yang sebagian besar anggotanya adalah warga daerah condongcatur. Dimana daerah Perumnas Condongcatur banyak usaha penjualan makanan/ warung makan karena banyak kos-kosan untuk melayani kebutuhan mahasiswa, karena daerah Condong catur berdiri beberapa Universitas yaitu UPN Veteran, AMIKOM dan UII Fakutas Ekonomi, sehingga sabun cuci piring diperlukan di usaha penjual makan. Di sekitar UPN Veteran, AMIKOM dan UII juga banyak terdapat guest house untuk menginap orangtua saat wisuda atau saat menengok putra-putri nya yang sedang kuliah dan sabun padat sangat diperlukan di guest house tersebut, Pelatihan Teknologi Kimia Terapan sangat tepat untuk memenuhi kebutuhan masyarakat. Kami melakukan pelatihan pembuatan sabun cair, sabun mandi herbal dan tepung ampas kelapa dengan harapan dapat memberikan tambahan ilmu kepada masyarakat di sekitar condongcatur sehingga warga dapat mengerti cara pembuatannya yang nantinya dapat diaplikasikan untuk pemberdayaan warga dalam bidang ekonomi, yaitu pembuatan sabun cair cuci piring dan sabun mandi herbal serta tepung ampas kelapa untuk diproduksi dalam skala home industry.

Sabun cair cuci piring merupakan sabun yang dibuat dari bahan dasar zat aktif permukaan (ZAP). Zat aktif permukaan dapat mengubah tegangan muka suatu larutan. Sifat-sifat khusus yang dimiliki zat aktif adalah pembasahan, daya busa dan daya emulsi. Pencucian adalah proses membersihkan suatu permukaan benda padat dengan bantuan larutan pencuci melalui suatu proses kimia-fisika yang disebut deterjensi. Sifat utama dari kerja deterjensi adalah membasahi permukaan yang kotor kemudian melepaskan kotoran. Detergen cair biasanya menggunakan bahan pelarut organik sebagai pelengkap dan penambah daya deterjensi yang diperlukan untuk kotoran-kotoran yang sulit dihilangkan atau berlemak.

Sabun mandi dibuat dari minyak nabati atau lemak dengan penambahan formula basa seperti soda kaustik. Bahan-bahan herbal sekarang banyak ditambahkan ke dalam pembuatan sabun mandi karena sifat bahan herbal yang alami dan aman digunakan seperti minyak zaitun dan sebagainya. Sabun mandi bermanfaat untuk menghilangkan minyak dan kotoran di tubuh sehingga tubuh menjadi bersih. Sabun mandi herbal, disamping dapat membersihkan kotoran juga dapat menghaluskan kulit. 
Diterbitkan oleh Lembaga Pengabdian kepada Masyarakat

Universitas Ahmad Dahlan Yogyakarta

\section{B. TINJAUAN PUSTAKA}

\section{Penggolongan Sabun}

Ditinjau dari bahan dasarnya sabun dapat digolongkan ke dalam dua kelompok besar, yaitu:

a. Sabun yang dibuat dari asam lemak dan logam yang digaramkan. Logam yang digunakan biasanya dari jenis logam alkali, misalnya natrium dan kalium. Jenis sabun yang dihasilkan diantaranya adalah sabun mandi padat dan krim.

b. Sabun yang dibuat dari bahan dasar zat aktif permukaan (ZAP). Jenis ZAP yang digunakan biasanya dari jenis anionik dan menghasilkan sabun dalam bentuk cair. Zat aktif mengubah tegangan permukaan suatu larutan. Sifat-sifat khusus ZAP adalah pembasahan, daya busa, dan daya emulsi. Zat aktif permukaan anionik adalah zat aktif permukaan yang akan terionisasi dan membawa muatan negatif bila dilarutkan dalam air. Salah satu contohnya adalah alkil benzena sulfonat. Senyawa ini memiliki rantai lurus panjang yang bercabang dan dibuat dengan mereaksikan parafin dengan benzena. Beberapa sifatnya yang terpenting adalah: tahan sadah karena tidak mengandung gugus karboksilat dan tahan asam maupun alkali. Sebagai contoh misalnya alkil benzo natrium sulfonat.

\section{Pencucian}

Pencucian adalah proses membersihkan suatu permukaan benda padat dengan bantuan larutan pencuci melalui suatu proses kimia-fisika yang disebut deterjensi. Sifat utama dari kerja deterjensi adalah membasahi permukaan yang kotor kemudian melepaskan kotoran. Pembahasan berarti penurunan tegangan muka padatan-cair. Pencucian atau permukaan dan antar pelepasan kotoran berlangsung dengan jalan mendispersikan dan mengemulsi kotoran, lalu dengan bantuan aksi mekanik kotoran menjadi terlepas dari permukaan benda padat.

Kotoran padat dapat melekat karena adanya pengaruh: katan minyak, gaya listrik statik, dan ikatan hidrogen. Penambahan sedikit alkali membantu daya deterjensi dari sabun, tetapi dapat mendorong terjadinya hidrolisa. Alkali digunakan untuk menjaga $\mathrm{pH}$ larutan. Deterjen cair biasanya menggunakan bahan pelarut organik sebagai pelengkap dan penambah daya deterjensi dan diperlukan untuk kotoran-kotoran yang sulit dihilangkan atau berlemak.

\section{Zat Pembantu dan Pengisi}

Dalam pembuatan sabun peran zat pembantu dan pengisi sangat besar karena akan sangat menentukan mutu dan kenampakan sabun yang akan dijual. Zat-zat yang biasa digunakan adalah:

a. Garam, berfungsi sebagai pengental. Semakin banyak jumlah garam yang digunakan makan sabun yang dihasilkan akan semakin kental. Garam alkali berfungsi untuk mengatur $\mathrm{pH}$ larutan sabun dan penambah daya deterjensi.

b. Zat pemberi busa, untuk meningkatkan pencucian yang bersih, sebab tanpa busa kemungkinan besar sabun telah mengendap sebagai sabun kalsium atau sabun tidak larut lainnya. 
c. Etylen Diamine Tetra Acid (EDTA), sebagai pengikat logam sadah dan pengawet.

d. Pewangi, untuk memberikan aroma tertentu sesuai selera dan meningkatkan daya tarik serta daya jual sabun.

e. Zat warna, memberi warna pada sabun agar mempunyai penampilan menarik.

Inovasi tentang sabun mandi herbal banyak dikembangkan atau diteliti oleh akademisi terkait bahan herbal tambahan yang digunakan dengan kelebihannya masingmasing. Wiji dan Siwi (2014), meneliti tentang pemanfaatan ekstrak etanol dan dekokta kulit manggis sebagai pewarna terhadap kualitas sabun organik berbasis minyak jelantah dimana Minyak jelantah dimurnikan dengan ekstrak mengkudu, kulit manggis diekstraksi dengan maserasi dan dekok, kulit jeruk purut diisolasi dengan destilasi. Kemudian dibuat formulasi menjadi sabun dan dilakukan uji evaluasi kemudian diamati pengaruh ekstrak kulit manggis terhadap hasil uji evaluasi sabun yang menentukan kualitas sabun. Hasil dari penelitian menunjukkan kualitas sabun yang dihasilkan sesuai dengan SNI. Tuty, dkk (2015) melakukan penelitian pembuatan sabun mandi transparan dari ekstrak teh hijau, seperti diketahui bahwa teh hijau bermanfaat sebagai anti oksidan, anti inflamasi dan anti kanker serta kecantikan. Kandungan ekstrak teh hijau sebanyak $2 \%$ menghasil produk sabun yang sesuai dengan standar kualitas sabun padat dan sangat potensial untuk dikembangkan dan diproduksi.

Tepung ampas kelapa merupakan produk turunan dari pemanfaatan buah kelapa yang kaya akan manfaat. Tepung ampas kelapa juga menjadi solusi pemanfaatan ampas kelapa yang telah diambil santannya menjadi produk yang bermanfaat. Penelitian tentang pemanfaatan bahan alam untuk diolah menjadi bahan pangan khususnya tepung telah dilakukan oleh Endah, dkk (2015), yaitu tepung dari buah kimpul.

\section{Metodologi}

Materi berupa print out yang berisi alat, bahan, cara kerja serta keterangan tentang masing-masing bahan yang digunakan. Metode pelaksanaan berupa penjelasan teoritis dan praktek membuat sabun cair cuci piring, sabun mandi herbal dan tepung ampas kelapa yang berkualitas.

\section{Bahan pembuatan sabun cair cuci piring;}

1. Alkil benzena sulfonat (ABS)

2. Soda kostik $(\mathrm{NaOH})$

3. Zat pemberi busa (Texapon)

4. Garam dapur $(\mathrm{NaCl})$

5. Zat warna

6. EDTA

7. Pewangi: Jasmine, Blueberry, Lemon, Rose

\section{Bahan pembuatan sabun mandi herbal;}
1. $\mathrm{NaOH}$
$35 \mathrm{gr}$
2. Air
$69 \mathrm{gr}$
3. Castor oil
4,5 gr
4. Minyak kelapa
$143 \mathrm{gr}$ 
Diterbitkan oleh Lembaga Pengabdian kepada Masyarakat

Universitas Ahmad Dahlan Yogyakarta
5. Minyak sereh
$8 \mathrm{gr}$
6. Minyak zaitun
$4 \mathrm{gr}$

\section{Bahan pembuatan tepung ampas kelapa;}

Ampas kelapa segar yang sudah diambil santannya

\section{Pembuatan sabun cair cuci piring;}

Cara pembuatan sabun cair cuci piring yaitu dengan memasukkan dan mencampur email dan sebagian sodium sulfat $(100 \mathrm{ml})$ dalam ember dan diaduk secara terus-menerus hingga homogen. Memasukkan aquades sedikit demi sedikit sampai 50\% nya. Memasukkkan comperland dan mengaduknya secara perlahan. Kemudian memasukkan campuran asam sitrat dan air 50\%. Memasukkan sisa sodium sulfat $50 \mathrm{ml}$, selanjutnya menambahkan pewarna sebanyak 5 tetes atau secukupnya. Memasukkan campuran Propilen Glikol dan parfum sesuai selera yang dikehendaki (Jasmine, Blueberry, Lemon, Rose). Memasukkan EDTA dan sisa aquades sedikit demi sedikit sambil terus diaduk. Sabun cair yang sudah jadi dimasukkan ke dalam botol, untuk dapat digunakan sabun harus didiamkan kurang lebih 12 jam (waktu yang dibutuhkan untuk reaksi penyabunan/ saponifikasi).

\section{Pembuatan sabun mandi herbal;}

Timbang aquades dan $\mathrm{NaOH}$, tuangkan ke dalam air sedikit demi sedikit, aduk hingga larut. Setelah larut semuanya, panaskan sampai suhu $90{ }^{\circ} \mathrm{C}$. Timbang minyak kelapa, masukkan dalam baskom alumunium, kemudian masukkan larutan $\mathrm{NaOH}$ pelanpelan sambil dimixer selama 15 menit. Matikan mixer jika bahan sudah kental dan jika dites tidak menepel di sendok logam. Selanjutnya masukkan bahan lainnya ke dalam sabun dasar, aduk manual dengan pengaduk sampai rata. Siapkan cetakan plastik. Tuangkan sabun kental tadi ke dalamnya. Diamkan sabun dalam cetakan selama 3-6 hari. Kemudian keluarkan dari cetakan. Bungkus dengan plastik dan dipacking. Simpan sabun 4-6 minggu sebelum digunakan.

\section{Pembuatan tepung ampas kelapa;}

Daging buah kelapa dibuang kulit terluarnya (yang berwarna coklat), tujuannya agar dihasilkan tepung yang berwarna putih. Setelah bersih dari kulit terluar, selanjutnya daging kelapa diparut. Parutan kelapa diberi air secukupnya, diperas untuk diambil santannya. Ampas kelapa yang masih agak basah diblender menggunakan blender listrik dan tanpa tambahan air, hingga ukuran ampasnya kecil seperti tepung. Setelah ukurannya sesuai keinginan, masukkan ampas ke dalam wajan, panaskan dengan api kecil sambil diaduk-aduk hingga kering, dan dijaga jangan sampai berubah warna. Usahakan warnanya tetap putih. Setelah kering, tepung ampas diayak menggunakan ayakan dengan ukuran sesuai keinginan. Sisa tepung yang tidak lolos ayakan dapat dikecilkan lagi ukurannya menggunakan blender, lalu diayak kembali.

\section{HASIL DAN PEMBAHASAN}


Antusiasme Ibu-ibu 'Aisyiyah Perumnas Condongcatur Depok Sleman dalam mengikuti pelatihan tepat guna sangat besar, antara lain banyak ibu-ibu yang hadir serta mau turut serta dalam acara tersebut. Partisipasi ini terlihat pada pelatihan tepat guna pembuatan sabun cair, sabun padat dan tepung ampas kelapa yang terdapat pada gambar di bawah ini:

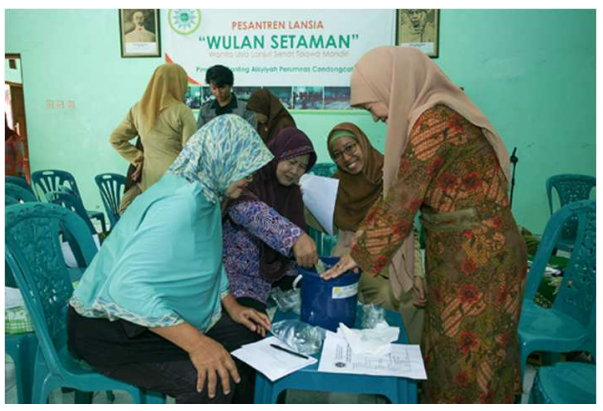

Gambar 1. Praktek membuat sabun cair

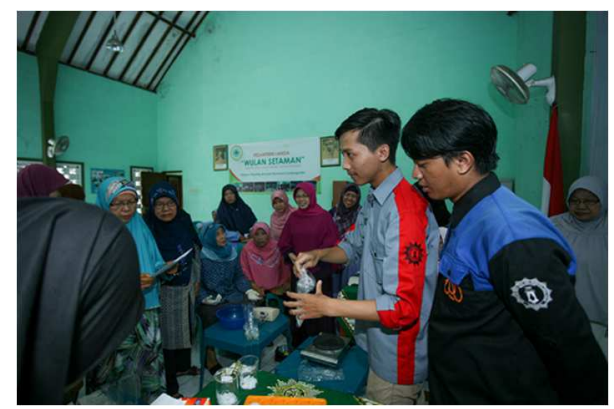

Gambar 2. Praktek membuat sabun padat

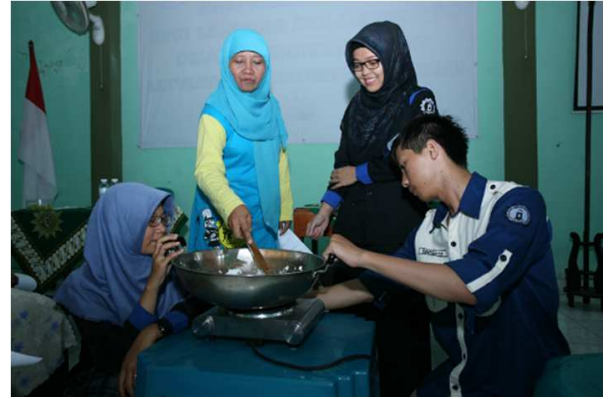

Gambar 3. Praktek membuat tepung ampas kelapa

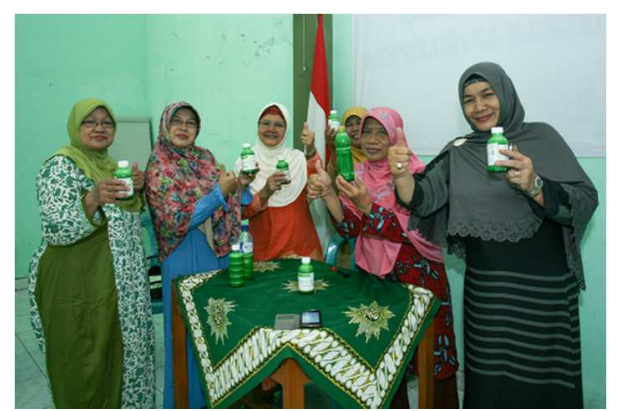

Gambar 4. Produk sabun cair

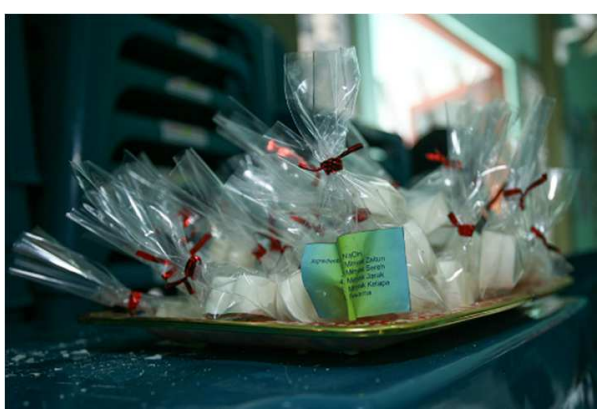

Gambar 5. Produk sabun mandi herbal

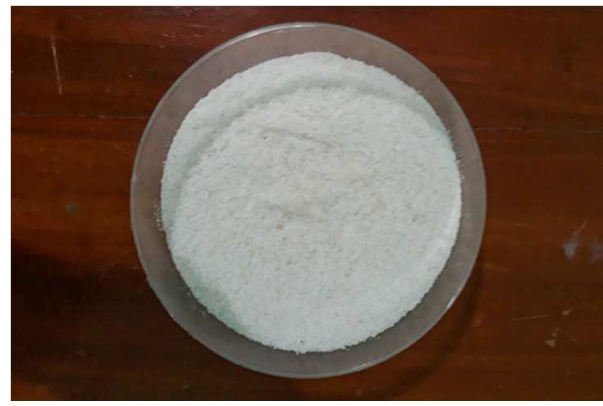

Gambar 6. Produk tepung ampas kelapa 
Diterbitkan oleh Lembaga Pengabdian kepada Masyarakat

Universitas Ahmad Dahlan Yogyakarta

\section{KESIMPULAN}

Pelatihan teknologi kimia terapan sangat bermanfaat untuk warga dan perlu diterapkan di masyarakat. Dengan pelatihan ini masyarakat dapat mengembangkan produkproduk sabun cair cuci piring, sabun mandi herbal dan tepung ampas kelapa ke arah komersial sebagai lahan usaha. Hasil praktek sabun cair cuci piring 1 resep bahan dapat menjadi 6 botol volume $150 \mathrm{ml}$. Sabun mandi herbal 1 resep bahan akan menjadi 12 buah sabun dengan ukuran deameter $3 \mathrm{~cm} .1 \mathrm{~kg}$ kelapa parut akan diperoleh 500 gram tepung ampas kelapa berkualitas.

\section{E. UCAPAN TERIMAKASIH}

Kami ucapkan Terimakasih kepada Pimpinan Ranting 'Aisyiah Perumnas Condongcatur, Depok, Sleman, Ibu Hj. Noeryani Nadjib yang telah memberi kesempatan tempat, waktu, sehingga pengabdian bisa berlangsung dengan lancar.

\section{DAFTAR PUSTAKA}

Amoo, I.A., 2004, Effect of roasting on the chemical compisition of coconut (Cocos nucifera) seed fluor and oil, Journal of Food, Agriculture, and Environment.

Anggraini, T., Ismanto, S.D., dan Dahlia. (2015). The Making of Transparent Soap from Green Tea Extract. International Journal on Advanced Science Engineering Information Technology. Vol. 5 (2015), No. 4, ISSN: 2088-5334.

Hart. H., 1983. Organic Chemistry A Short Course, Sixth Edition.

Ketarens,S.,1986, pengantar Teknologi minyak dan lemak pangan, UI Press, Jakarta.

Krishna, G.A.G., Raj, G., Bhatnagar, A.S., Kumar, P.P.K., and Chandrashekar, P., 2010, "Coconut Oil: Chemistry, Production and Its Applications-A Review", Indian Coconut Journal, pp.15-27.

Kusumaningsih, W.S. dan Hastuti, S. (2014), “ Pengaruh Ektrak Etanol dan Dekokta kulit manggis sebagai pewarna terhadap kualitas sabun organik transparan berbasis minyak jelantah yang dimurnikan dengan ektrak mengkudu dengan pengaroma kulit jeruk purut ( Citrus Hystrix). Indonesia Journal On medical Science, Volume 1, N0 2, ISN: 2355 -1313, pp. 47 -54

Morrison and Boyd, "Organic Chemistry", Fourth Edition.

Rozi, M. (2013) , Formulasi Sediaan Sabun mandi transparan minyak atsiri Jeruk nipis dengan Cocamed Dea sebagai surfactan, skripsi, Fakultas farmasi Universitas Muhammadiyah Surakarta.

Riswitanto, 2009, Kimia Organik, Penerbit Erlangga, Jakarta.

Santoso, Imam, 2014, Petunjuk Praktikum Kima Terapan, Prodi Teknik Kimia, FTI, Universitas Ahmad Dahlan, Yogyakarta.

Sulistiawati, E., Santosa, I., Yunizar, R.A.P.S., dan Saka, A.A. (2015). Pengaruh Suhu pada Pengeringan Tepung Kimpul (Xanthosoma sagittifolium). Chemica. Vol. 2. No. 2. Desember 2015. ISSN: 2355-8776. 
